\title{
The biodiversity audit approach challenges regional priorities and identifies a mismatch in conservation
}

\author{
Paul M. Dolman*, Christopher J. Panter and Hannah L. Mossman \\ School of Environmental Sciences, University of East Anglia, Norwich, UK
}

\begin{abstract}
Summary
1. Despite a strong uptake of evidence-based approaches, conservation often proceeds from a grossly incomplete understanding of species priorities. To optimize conservation impact within a biogeographical region, quantitative knowledge is needed of the species present, which should be prioritized, and the management interventions these require. The next challenge is to avoid a proliferation of competing species plans, or conversely, a lack of detail within generic habitat-based approaches.

2. We present a methodology for biodiversity auditing. We quantified regional biodiversity by systematically collating available species records, allowing objective prioritization. We collated autecological information to integrate multiple species into management guilds with shared requirements, providing evidence-based guidance for regional conservation.

3. For two regions of Eastern England, Breckland $\left(2300 \mathrm{~km}^{2}\right)$ and The Broads $\left(2000 \mathrm{~km}^{2}\right)$, we collated 0.83 and 1.5-million records, respectively. Numbers of species (12 845 and 11067 ) and priority species (rare, threatened, designated or regionally restricted: 2097 and 1519 , respectively) were orders of magnitude greater than previously recognized. Regional specialists, with a UK range largely or entirely restricted to the region, were poorly recognized posing a risk of regional homogenization.

4. A large body of autecological information existed for priority species and collating this allowed us to define cross-taxa management guilds. Numbers of priority species requiring different combinations of ecological processes and conditions were not matched by current conservation practice in Breckland. For example, the current agri-environment agreements for designated grass heaths potentially catered for only $15 \%$ of the 542 priority species and $21 \%$ of 47 regional specialists that could potentially benefit from evidence-based management. A focus on vegetation composition rather than the ecological requirements of priority species underpinned this failure.

5. Synthesis and applications. The biodiversity audit approach provides an objective model for prioritization and cost-effective conservation, applicable to regions of Europe where biodiversity has been well characterized. By using this approach to collate available information, management guilds with similar requirements can be defined across taxa, providing evidencebased guidance for regional conservation.
\end{abstract}

Key-words: citizen science, conservation effectiveness, conservation management, evidencebased conservation, habitat management, management guild, multispecies assemblage, regional distinctiveness, semi-natural habitat

\section{Introduction}

Since the need for evidence-based biodiversity conservation (Sutherland et al. 2004) was advocated, uptake of

*Correspondence author. E-mail: p.dolman@uea.ac.uk such approaches has been strong. In the UK, for example, an evidence-based approach is now embedded in governmental conservation policy (NE 2008). Such practice is supported by an increasing body of systematic reviews and compilations of practitioners' experience (for examples, see the Collaboration for Environmental Evidence, the Centre for Evidence-Based Conservation and the 
journal Conservation Evidence). However, although techniques to investigate the effectiveness of particular interventions are well developed, decisions regarding which assemblages and species to target at a site or regional level generally proceed from a woefully incomplete understanding.

For selected species, detailed understanding of their ecology and demographic drivers has provided evidence for effective, targeted interventions that can underpin population recovery, for example, of butterfly species (Asher et al. 2001) or birds such as corncrake Crex crex (O'Brien, Green \& Wilson 2006) and little bustard Tetrax tetrax (Bretagnolle et al. 2011). However, attention has focused on vertebrates and plants, supplemented by a few invertebrate groups (most usually Lepidoptera, Odonata, increasingly Hymenoptera) that have benefited from effective advocates (Clark \& May 2002; Seddon, Soorae \& Launay 2005). Other species, when considered, are an idiosyncratic selection of taxa with no evidence as to why these should be chosen over the unquantified but presumably large numbers of other species present. In anthropogenic landscapes, conservation proceeds by management interventions, often mimicking traditional land-use practices (Wright, Lake \& Dolman 2012), but without comprehensive understanding of which, or how many, species are actually present, or of the range of interventions required by the full complement of species of conservation concern.

Improving the quality of remaining habitat fragments, increasing their size and restoring ecological connectivity are necessary for biodiversity resilience (Lawton et al. 2010). But within any particular biogeographical region, what habitats should we be creating and for what biodiversity? For finite conservation resource to be deployed in a defensible and cost-effective manner requires fuller understanding of the species present, of species priorities and of their management requirements.

Having clarified species priorities, the next challenge is to avoid either a proliferation of competing species plans or generic habitat-based approaches that lack necessary detail. Multiplication of species-based action plans and the challenge of reconciling prescriptions at site-based scales make habitat-based approaches increasingly attractive. Such tension is evident in the UK between the 1150 Biodiversity Action Plan (BAP) species and broader guidance in the 65 habitat BAPs (BRIG 2007), and in the United States between the Endangered Species Act and ecosystem-based approaches (Lindenmayer et al. 2007). Habitat-based approaches are further encouraged by the increasing emphasis on Ecosystem Services (MEA 2005; Defra 2011; NEA 2011). However, applying generic prescriptions for habitat management without knowing what species are present, which are priorities for conservation and what their ecological requirements are, may accelerate the loss of biodiversity from designated sites. A shift to generic habitat prescriptions may be particularly detrimental to poorly understood invertebrates with exacting requirements. This tension may be resolved by understanding, analysing and integrating the ecological and management requirements of multiple species, to define management guilds with shared responses to interventions.

Here we outline a novel evidence-based approach to biodiversity analysis, prioritization and conservation. We present a systematic methodology for the bioregional audit of biodiversity, cutting across landscapes and ecosystems, to quantify the biodiversity present, objectively identify conservation priorities and provide integrated guidance for their management. We show how the scattered autecological information can be collated and synthesized for large numbers of priority species, to define guilds with shared requirements for ecological structures, processes and the management actions needed to sustain these requirements. We illustrate this biodiversity audit methodology with analysis from two contrasting biogeographical regions in Eastern England, Breckland, a lowrainfall region supporting important grass heath habitats and The Broads, an internationally important wetland complex.

\section{Materials and methods}

\section{STUDY AREAS}

Breckland (Fig. 1) is a region of c. $1000 \mathrm{~km}^{2}$, characterized by a semicontinental climate, sandy soils, a long history of low-intensity, episodic arable cultivation, extensive livestock grazing and a nationally unique biota that includes numerous Mediterranean and continental species, as well as coastal elements rarely found inland (Dolman \& Sutherland 1992; Dolman, Panter \& Mossman 2010). Fluctuating waterbodies support fen and relict periglacial biota, and extensive conifer afforestation has further diversified the landscape (Eycott, Watkinson \& Dolman 2006). In contrast, The Broads, c. $800 \mathrm{~km}^{2}$, is a complex of internationally important wetlands, comprising grazing marsh, fen, wet woodland and open water habitats (BA 2009).

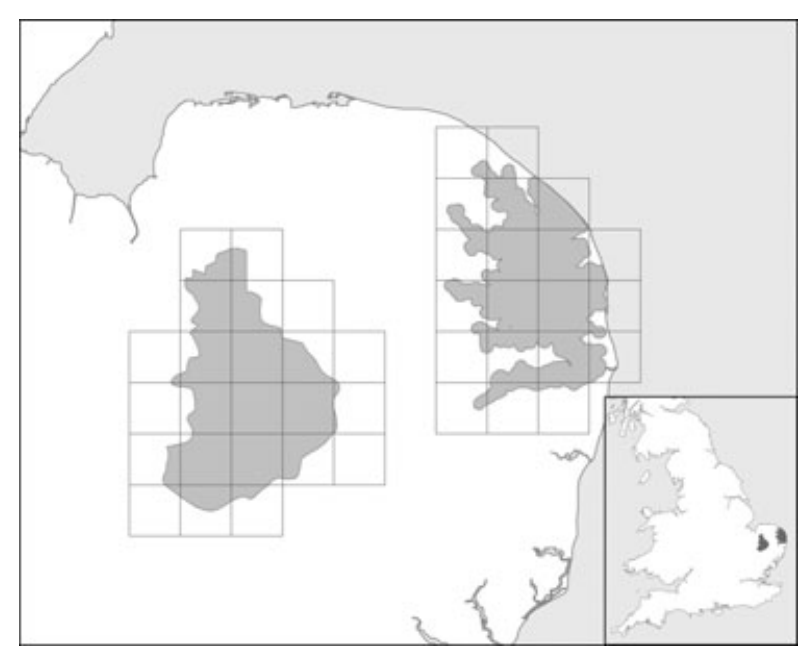

Fig. 1. Locations of Breckland and the Broads study areas, showing 10-km squares, Breckland National Character Area and Broads Biodiversity Action Plan area (shaded). 
QUANTIFYING REGIONAL BIODIVERSITY AND CONSERVATION PRIORITIES

Our approach integrated ecology and citizen science, collating large numbers of observations made by members of the public, scattered autecological information in the literature and the expert knowledge of amateur naturalists (summarized in Fig. 2). For each region, we compiled all available species observations (records) from Local Biological Records Centres, the National Biodiversity Network (NBN) gateway, national and county natural history and recording societies whose records were not available via NBN, and unpublished documents or reports. Taxonomic records were managed using RECORDER 6 software (Joint Committee for Nature Conservation, Peterborough, UK).

Although the majority of records are resolved to a spatial resolution of $1 \mathrm{~km}$ or finer, some taxa were only mapped to tetrad (e.g. some vascular plant and bird data sets) or even $10-\mathrm{km}$ square resolution (e.g. many historic records). Species records in Breckland were examined across the twenty-three $10-\mathrm{km}$ Ordnance Survey grid squares that were wholly or partly included within the Breckland National Character Area (NCA) defined by Natural England (Fig. 1). For Breckland, data were analysed over the full area of data collation, of which $56 \%$ comprised the NCA. For The Broads, data were collected for the twenty $10-\mathrm{km}$ grid squares that encompass The Broads BAP area (Fig. 1). For The Broads, only those tetrad and $1-\mathrm{km}$ resolution records within or intersected by the boundary were considered in the analysis, plus species records only resolved to $10-\mathrm{km}$ resolution, for which only those $10-\mathrm{km}$ squares that were entirely or largely $(>75 \%)$ within the BAP area were retained.

Aggregates of microspecies were treated as single species. Intraspecific taxa (subspecies, recognized forms or varieties) were aggre-

\section{The Biodiversity Audit Approach}

Establish stakeholder group and steering committee (for Breckland and The Broads comprised representatives from Natural England, Broads Authority, Brecks Partnership, Forestry Commission, Wildlife Trusts, County Biodiversity Partnerships, County Records Centres, PlantLife)

Define region and boundary e.g. National Character Area (JCA), Biodiversity Action Plan Area or Nature Improvement Area (NIA)

\begin{tabular}{|l|}
\hline \multicolumn{1}{|c|}{ Species Audit } \\
\hline Compile all available species records (using \\
Recorder software), including those from \\
local Biological Records Centres, NBN \\
gateway, national and county natural history \\
societies, plus documents/reports not \\
captured by recording networks (e.g. for \\
Breckland and the Broads, from Natural \\
England, the Broads Authority, Defence \\
Estates, Forestry Commission) \\
\hline
\end{tabular}

Validate provisional species (in Breckland by a taxonomist workshop and correspondence with 50, in The Broads 20, recorders and taxonomists) to highlight suspect and missing species: refine record data-base as necessary

Confirm final species list

Identify regional specialists (i.e. entirely or largely restricted, primary stronghold) through key words, literature, consultation; validated for specific groups by Atlas and NBN mapping

Generate list of priority species using status designations (from JNCC), provisional Red Data lists, plus regional specialists

\section{Management Audit}

Collate autecological information for priority species from accounts in Recorder software, Atlas accounts, specialist literature, supplemented where necessary by consultation with expert natural historians. Code each species against a consistent set of ecological processes and structures

Classify management guilds to define crosstaxa groups of species with shared requirements for processes and micro-habitat structures.

Quantify numbers of priority species and regional specialists requiring different approaches to management

Management workshops with landowners, site managers and conservation advisers: present Biodiversity Audit results, discuss management prescriptions suitable for guilds, collate experience of management outcomes (e.g. in Breckland a workshop of heathland managers, and a workshop of arable managers and advisers)

Compare guild requirements to current practice, offer recommendations

\section{Dissemination}

Through on-line report, media coverage, local engagement, presentations to stakeholder groups including local Biodiversity Partnerships; provide summary guidance on prescriptions to conservation advisers, land-owners and site managers; notify natural history societies and recorder networks of under-recorded groups and sites

Fig. 2. Summary of the biodiversity audit methodology. 
gated with the parent species unless a conservation designation applied solely to a subspecific taxon. Taxa are hereafter referred to as 'species' for simplicity. While all records submitted to Local Records Centres are vetted by county recorders, with specimens generally required to substantiate new regional or subcounty records, NBN data included unvalidated records. Initial species lists were therefore validated by panels with expertise in species identification for a particular group and experience of recording in that region; these included many of the county recorders for particular taxonomic groups. Panels were asked to comment on any species that they considered unlikely to have occurred in the region: 47 species in Breckland and 72 species in The Broads considered to be erroneous were removed from further analysis. Validated species lists retained authenticated historic records of species now considered locally extirpated or nationally extinct.

Species of conservation priority were recognized according to UK designations as:

1. All UK BAP species.

2. Global and UK Red Data Book (RDB), except Least Concern.

3. Nationally Rare (15 or fewer $10-\mathrm{km}$ squares in Great Britain), Nationally Scarce (16-100 10-km squares, or Nationally Notable: A (30 or fewer $10-\mathrm{km}$ squares) and Nationally Notable: B (30100 10-km squares).

4. Red and Amber listed birds (UK-specific species of conservation concern, Eaton et al. 2009)

Species designations were obtained from the UK Joint Nature Conservation Council (JNCC 2011), the provisional UK RDBs for fungi (361 species, Evans, Henrici \& Ing 2006), lists of Nationally Notable species for Arachnida (Harvey, Nellist \& Telfer 2002) and Orthoptera and allies (Haes \& Harding 1997).

Species were also considered to be conservation priorities if their national distribution was entirely $(100 \%$ of UK range at $10-\mathrm{km}$ resolution) or largely ( $\geq 80 \%$ but $<100 \%$ of UK $10-\mathrm{km}$ range) restricted to the region or if the region supported a primary stronghold for the species within the UK $(\geq 50 \%$ but $<80 \%$ of UK $10-\mathrm{km}$ range). Candidate regional specialists were identified from a wide range of unpublished and published sources, searches of recorder species accounts using regional keywords and suggestions from validation panels. Candidate regional specialists were then vetted by calculating the number of regional $10-\mathrm{km}$ grid squares with records of presence, as a percentage of the total UK (excluding Northern Ireland) grid squares in which the species has been found. UK distributions were assessed using atlases of recorded UK population distributions, where available, or NBN distribution maps.

\section{ANALYSIS OF ECOLOGICAL REQUIREMENTS OF PRIORITY SPECIES TO CONSTRUCT MULTISPECIES MANAGEMENT GUILDS}

For the Breckland biogeographical region, we collated autecological understanding for all validated conservation priority species. We used this information to define 'management guilds' - taxonomically diverse groups of species with common requirements in terms of ecological processes and physical conditions, with a focus on potential management actions. Constituent species may not necessarily occur together as a coherent assemblage, for example, where more detailed requirements, such as soil $\mathrm{pH}$, differ but are assumed to benefit from the same management prescriptions applied across site and landscape scales.
Species were first assessed for their association with 27 broad habitat types, based on the UK landcover mapping programme (Fuller et al. 2002), with further ecological resolution where appropriate, for example, separating coastal shingle and dune. Species were then assessed for their ecological requirements, in terms of positive or negative associations with 48 microhabitats and structures (e.g. deadwood, bare ground, nectar resources) and 28 ecological processes (that create or modify habitat microhabitat structure and suitability, such as intense grazing or nutrient enrichment) (see Table S1, Supporting information). For phytophagous and parasitic invertebrates, ecological information for host species was also collated. Autecological information was compiled from a wide range of published and documentary sources, including the Invertebrate Site Register, RDBs, atlases, reviews of taxonomic groups and specialist journal publications, supplemented by personal knowledge provided by taxonomic experts. Coding was carried out by one individual (CP) to ensure consistent interpretation of sources. All sources are detailed in (Dolman, Panter \& Mossman 2010).

The resulting matrix of species autecological information was used as an evidence base for an iterative process in which management guilds were defined according to shared requirements, and species were progressively assigned to management guilds. Management guilds comprised fungi, lichens, lower and higher plants, invertebrates, amphibians, reptiles, fish, bats and rodents. We did not classify other mammals or birds, for which ecological requirements and management prescriptions must generally be considered at greater spatial scales. Species were first classified into six categories along successional (open to wooded) and hydrological (dry to aquatic) gradients: open (all dry terrestrial habitats lacking a wooded canopy), open with scrub, open woodland (including wood pasture, wood edge and glades), woodland, open wetland (including open water, running water and fen) or wet woodland (shaded wetland). Within each of these, species' requirements for, or intolerance of, structures and processes were assessed so that management guilds could be formulated based on combinations of these options. Where species information was limited to an association with a single habitat or structure, the species was assigned to a broad guild. We recognize that although this methodology was applied consistently and objectively after systematic collation of available data, it is nevertheless subjective and if repeated independently different management guilds may result. We considered this method preferable to classification of management guilds by clustering algorithms applied to the matrix of species by processes, owing to our intention that the guilds would have management relevance. We found that statistical clustering resulted in guilds of species with similar requirements, but not necessarily focussed on management actions.

\section{HABITAT ASSOCIATIONS}

To explore the extent to which groups of species mapped onto habitat-based approaches, we examined the uniqueness or overlap in their association across 18 coarse habitat classes: marine; brackish lagoons; salt marshes; sand dune and shingle; running waters; standing waters; fen and reedbed (including fen meadow, but not carr); bog and mire; wet grassland (including coastal grazing marsh); dry grasslands (including calcareous and improved); heath; arable; brownfield, gardens and waysides; quarries and pits (including chalk spoil); scrub; hedgerows; woodland 
(coniferous, mixed or deciduous, including coppice and wood pasture); and wet woodland (including fen carr). For all conservation priority species in each region, primary habitat association (s) were assigned to one or more of these 18 coarse habitat types, where evidence stated the species was primarily or frequently recorded in this habitat; secondary habitat association(s) (e.g. occasionally recorded or 'also known' from) were noted but are not analysed here. For each coarse habitat type in each region, we quantified the total number of conservation priority species for which it provides a primary association and the number of species for which it was the sole primary association.

\section{Results}

\section{DATA COLLATION}

We collated 830747 records for Breckland and 1507647 records for The Broads.

For both regions, taxonomic coverage achieved was broad, but nevertheless biased, with flowering plants comprising the largest proportion of records, $50 \%$ and $32 \%$ in Breckland and The Broads, respectively, compared with $0.03 \%$ and $0.69 \%$ of records for diatom and algal species (including charophytes). Contrary to our expectation that they would predominate, bird and mammals together contributed to only $7 \%$ and $8 \%$ of records in Breckland and The Broads, respectively, although these figures are disproportionate to their contribution to total species richness (3\% and 4\%). Arthropods comprised 35\% (290 761) and 46\% (693 089) of the records in Breckland and The Broads, respectively, less than their contribution to species richness $(64 \%, 56 \%)$. Moths contributed $41 \%$ and $43 \%$ of these arthropod records, but only $19 \%$ and $23 \%$ of arthropod species. Soil infauna including soil macro-invertebrates, were poorly recorded, with annelids comprising only $0.08 \%$ and $0.85 \%$ of all invertebrate records from Breckland and The Broads, respectively. Only three nematode records in total were obtained across both Biodiversity Audits.

\section{BIODIVERSITY IMPORTANCE OF A REGION}

In Breckland, 12845 species have been recorded, which included 2420 Diptera, 2251 Coleoptera and 1720 species of vascular plant (Table 1). In The Broads, records of 11067 species were collated, of which 1874 species were fungi (including fungoids), 1797 were Coleoptera and 1596 were Diptera.

Conservation had previously prioritized relatively few species within each region. For example, the English Nature BAP for Breckland (EN 2001) identified 45 species as priorities for conservation, of which $31 \%$ were vertebrates and 145 species of conservation concern $(57 \%$ vertebrates). In contrast, systematic collation of the evidence base available increased this by more than an order of magnitude to 2097 conservation priorities in Breckland (of which $1.3 \%$ were subspecific taxa). These include 321
BAP species (28\% of the UK BAP total and seven times the number previously collated) and 666 RDB species (Table 1), 15\% of all species designated as RDB in the UK. Similarly, the BAP for The Broads (BA 2009), presented as an exhaustive list of the BAP species present in the region, listed a total of 146 priority species, of which $45(31 \%)$ were vertebrates and $50(34 \%)$ were moths. However, biodiversity audit identified 1519 conservation priority species (of which $2.0 \%$ were subspecific taxa). Although this is in part attributable to wider definition of priority species (e.g. including all 491 RDB species as well as nationally rare and scarce) collated records identified 301 BAP species recorded from The Broads, twice the number previously recognized.

Seventy-two species from 19 Orders were found to be regionally restricted to Breckland (Table 1; Fig. 3), three times more than had previously been recognized as regionally distinctive (Rothera 1998). Breckland regional specialists included 21 species that were entirely restricted, eight largely $(\geq 80 \%$ ) restricted to the region and a further 43 species with primary population strongholds. Similar numbers of species (totalling 66 from 19 Orders) were found to be regionally restricted to The Broads within the UK, even though only seven orders were common between the two regions. Species recorded in The Broads included 31 that were entirely or largely restricted to the region, many more than had previously been recognized (BA 2009). Twenty-seven per cent of species restricted to The Broads and $21 \%$ of Breckland specialist species were BAP designated (Fig. 4). Nine species restricted to Breckland and six species restricted to The Broads had no formal conservation status in the UK, despite their highly restricted distribution that qualifies them as Nationally Rare (Fig. 4).

\section{HABITAT-BASED CONSERVATION}

Of the 2097 priority species recorded in Breckland and the 1519 priority species in The Broads, $13.7 \%$ and $7 \cdot 6 \%$ could not be assigned to one or more broad habitat types, either due to the paucity of ecological information or because the species had specialist requirements that could occur across the landscape (e.g. carrion). Of those priority species that could be coded for their habitat associations, $41 \%$ and $39 \%$ in Breckland and The Broads, respectively, were not unique to a single broad habitat (Table 2). Rather, species were associated with a mean $( \pm \mathrm{SD})$ of $2 \cdot 0 \pm 1 \cdot 2$ habitats in Breckland and with $2 \cdot 0 \pm 1 \cdot 1$ habitats in The Broads, with $10 \%$ and $9.3 \%$ of species, respectively being associated with four or more habitats. Thus the artificial classification of vegetation into habitats based on human land use, does not match the distribution of species. This emphasizes the importance of considering the ecological requirements of species, in terms of microhabitats and ecological processes, and supports the formation of cross-cutting management guilds. 
Table 1. Taxonomic composition of recorded biodiversity within The Broads (Bo) and Breckland (Bk). For each taxonomic group, the total number of species for which records were obtained; numbers of 'Rare' species comprising Red Data Book (RDB: both UK and global), Notable A and B, Nationally Rare or Scarce species and bird species on UK Red and Amber lists; numbers of conservation priority species comprising Rare species, those listed as priority species in the UK Biodiversity Action Plan (BAP) and regionally restricted species (full or subspecies) that are entirely or largely restricted to that region within the UK or have a primary population stronghold there are shown. Designations are not mutually exclusive. Source of designations (JNCC 2011)

\begin{tabular}{|c|c|c|c|c|c|c|c|c|c|c|}
\hline & \multicolumn{2}{|c|}{$\begin{array}{l}\text { Total numbers of } \\
\text { species }\end{array}$} & \multicolumn{2}{|l|}{ Rare } & \multicolumn{2}{|c|}{ BAP } & \multicolumn{2}{|c|}{$\begin{array}{l}\text { Regionally } \\
\text { restricted }\end{array}$} & \multicolumn{2}{|c|}{$\begin{array}{l}\text { Conservation } \\
\text { priorities }\end{array}$} \\
\hline & Bo & $\mathrm{Bk}$ & Bo & $\mathrm{Bk}$ & Bo & $\mathrm{Bk}$ & Bo & $\mathrm{Bk}$ & Bo & $\mathrm{Bk}$ \\
\hline Fungi* & 1874 & 1691 & 18 & 20 & 11 & 6 & 0 & 0 & 22 & 21 \\
\hline Lichens & 261 & 270 & 26 & 47 & 3 & 9 & 0 & 2 & 26 & 48 \\
\hline Algae and diatoms & 76 & 34 & 0 & 0 & 0 & 0 & 0 & 0 & 0 & 0 \\
\hline Charophtyes & 22 & 17 & 15 & 11 & 9 & 5 & 3 & 0 & 15 & 11 \\
\hline Bryophytes $^{\dagger}$ & 289 & 373 & 29 & 58 & 2 & 8 & 0 & 1 & 29 & 58 \\
\hline Vascular plants & 1313 & 1720 & 188 & 225 & 53 & 72 & 8 & 12 & 188 & 227 \\
\hline Molluscs & 147 & 131 & 11 & 11 & 9 & 9 & 3 & 0 & 12 & 11 \\
\hline Annelids & 30 & 12 & 2 & 0 & 0 & 0 & 0 & 0 & 2 & 0 \\
\hline Spiders (Araneae) & 366 & 388 & 36 & 62 & 4 & 9 & 4 & 3 & 36 & 66 \\
\hline True bugs (Hemiptera) & 388 & 487 & 46 & 54 & 2 & 1 & 7 & 4 & 47 & 54 \\
\hline Beetles (Coleoptera) & 1797 & 2251 & 403 & 658 & 11 & 21 & 13 & 27 & 403 & 660 \\
\hline Butterflies & 51 & 48 & 17 & 17 & 12 & 14 & 1 & 0 & 17 & 17 \\
\hline Moths & 1479 & 1538 & 96 & 77 & 91 & 94 & 9 & 6 & 179 & 164 \\
\hline True flies (Diptera) & 1569 & 2420 & 248 & 443 & 9 & 4 & 9 & 13 & 251 & 446 \\
\hline Hymenoptera & 424 & 564 & 55 & 110 & 10 & 11 & 3 & 1 & 60 & 114 \\
\hline Other arthropods & 470 & 512 & 25 & 20 & 4 & 1 & 4 & 2 & 26 & 22 \\
\hline Other invertebrates ${ }^{\S}$ & 45 & 22 & 1 & 1 & 1 & 1 & 0 & 0 & 1 & 1 \\
\hline Fish & 35 & 33 & 2 & 1 & 8 & 6 & 0 & 0 & 8 & 6 \\
\hline Herptiles** & 13 & 11 & 0 & 0 & 7 & 8 & 0 & 0 & 7 & 8 \\
\hline Birds & 362 & 275 & 171 & 149 & 41 & 30 & 2 & 1 & 176 & 151 \\
\hline Mammals $^{\dagger \dagger}$ & 56 & 48 & 2 & 2 & 14 & 12 & 0 & 0 & 14 & 12 \\
\hline Total & 11607 & 12845 & 1391 & 1966 & 301 & 321 & 66 & 72 & 1519 & 2097 \\
\hline
\end{tabular}

*Including fungoids, slime moulds;

$\dagger$ Mosses, liverworts;

$\$$ Tracheophyta: clubmosses, ferns, Spermatophytes;

IIncluding all other insect groups, millipedes, centipedes, crustaceans, other Arachnids;

$\S$ Including Bryozoan, Cnidaria, flatworms, rotifers;

**Reptiles, amphibians;

†'Including marine mammals.

For priority species in Breckland, analysis of available autecological evidence to define groups with common requirements resulted in 51 management guilds comprising 1662 species, $80 \%$ of all priority species (Figs 4 and 5). Of these guilds, 24 were associated with dry, terrestrial and 21 with wetland landscape elements, while two comprised species requiring damp conditions. The four remaining management guilds comprised species that occurred across ecotones spanning landscape elements with markedly different vegetation structure and or hydrology. A further group of 92 species (4\% of the total) were identified that had specific management-relevant ecological requirements, such as carrion or dung, but that could occur in a wide range of contexts; subsets of this group could be considered as additional guilds for conservation. The remaining unassigned species comprised 3\% (59 species) that were classified as unspecialized, $7 \%$ of species that had particularly specialist and unique requirements and so could not be placed into multispecies guilds and $6 \%$ that could not be assigned to a management guild due to paucity of ecological information.
The mean number of species per management guild was 33 (SD 36, range 2-147) and one or more regionally restricted species occurred in 20 of the management guilds. Previous conservation management priorities for the region emphasized the importance of intensive grazing combined with physical disturbance (Dolman \& Sutherland 1992). This was supported, with 115 priority species, including 11 regional specialists, placed in a management guild of species that require open conditions, with physical disturbance and intense grazing (Fig. 5). However, even greater numbers of priority species (133) and Breckland specialists (17) were allocated to a management guild of species requiring open terrestrial habitats affected by regular or frequent physical soil disturbance but receiving no or only light grazing. Many of these species are likely to have historically occurred either in intermittently cultivated fields, or in brown-field sites, but with appropriate management could be also catered for in designated grass heaths. The importance of this group for regionally distinctive biodiversity had not been recognized previously. Other important groups of priority species 
(a)

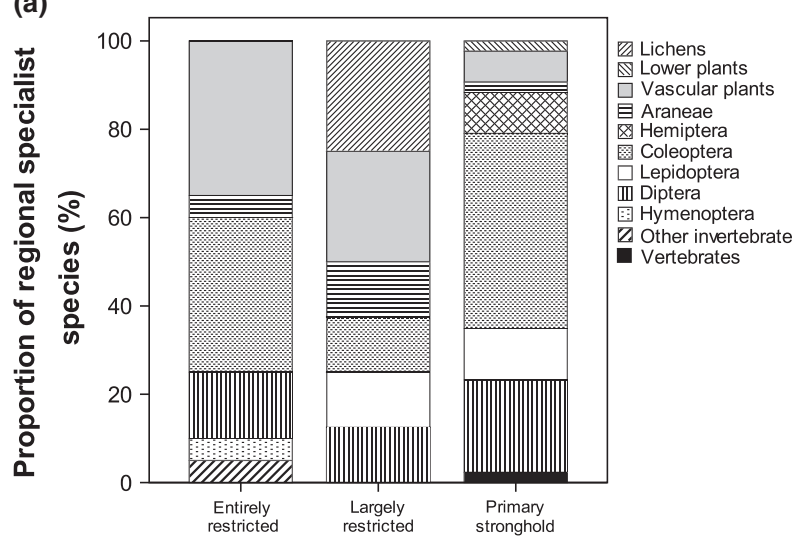

(b)

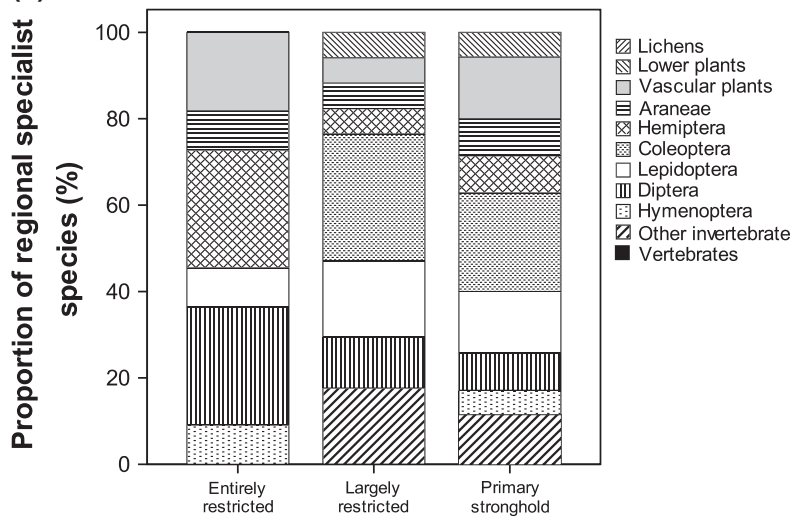

Fig. 3. Taxonomic composition of regionally restricted species for (a) The Broads, (b) Breckland, that are entirely restricted ( $n=14,21$, respectively), largely restricted (17, 8, respectively), or have a primary stronghold $(35,43$, respectively).

that were relatively neglected within this region included four guilds associated with deadwood and veteran trees, comprising 169 priority species but only two regional specialists. For wetland-associated species, quantitative analysis of management guilds provided support for interventions to remove encroaching scrub and woodland, as guilds of unshaded aquatic habitats comprised over five times as many priority species (441, including 11 regional specialists) than those of shaded wetlands or wet woodland (82 priority species, no regional specialists) (Fig. 6).

\section{MATCH AND MISMATCH IN CONSERVATION MANAGEMENT}

The majority of conservation management of dry, terrestrial areas in Breckland has focussed on two conservation prescriptions, practiced in different landscape elements. On grass heaths, livestock grazing principally by sheep, is widespread and supported by agri-environment agreements. However, $43 \%$ of the grass heath area received only light to moderate grazing (Dolman, Panter \& Mossman 2010). At best, this has the potential to provide conditions suitable for 80 priority species, including 10 regionally restricted species (Fig. 5). Further important guilds of priority species that could potentially be catered for by refining management prescriptions on grass heaths have been neglected by agri-environment agreements. Such management guilds included those requiring hard grazing in combination with physical soil disturbance (only applied to $<1 \%$ of the heath resource; Dolman, Panter \& Mossman 2010), those requiring structurally complex sward mosaics (which could be provided through vegetation recovery following mechanical turfremoval, or wide-amplitude temporal variation in grazing intensity), those requiring juxtaposition of grazed, disturbed conditions and ungrazed nectar sources, and corresponding guilds with similar requirements but also requiring proximity to scrub. Together, these comprised an additional 320 priority species, including 135 RDB and 20 regional specialists. Appropriate management of parts of grass heaths could also provide suitable conditions for the guild of species requiring physical disturbance of infertile soils but with no or only light grazing, plus similar species also requiring scrub; together comprising a further 142 priority species, including 17 regional specialists. Therefore, current public conservation investment through agri-environment schemes on the region's terrestrial semi-natural designated areas delivers just $15 \%$ of the priority species and $21 \%$ of the regional

Fig. 4. Unique and multiple designations of priority species recorded in The Broads and Breckland, showing numbers that are Biodiversity Action Plan, Red Data Book or Notable (including Nationally Notable, Rare and Scarce, and Bird: Red and Amber) or regionally restricted (entirely, largely or with a primary stronghold).

The broads
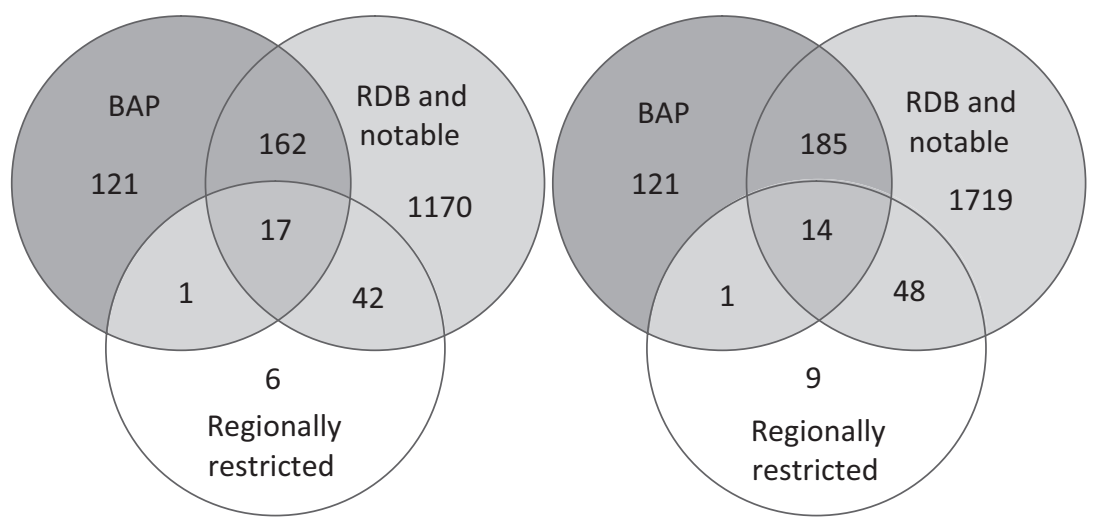


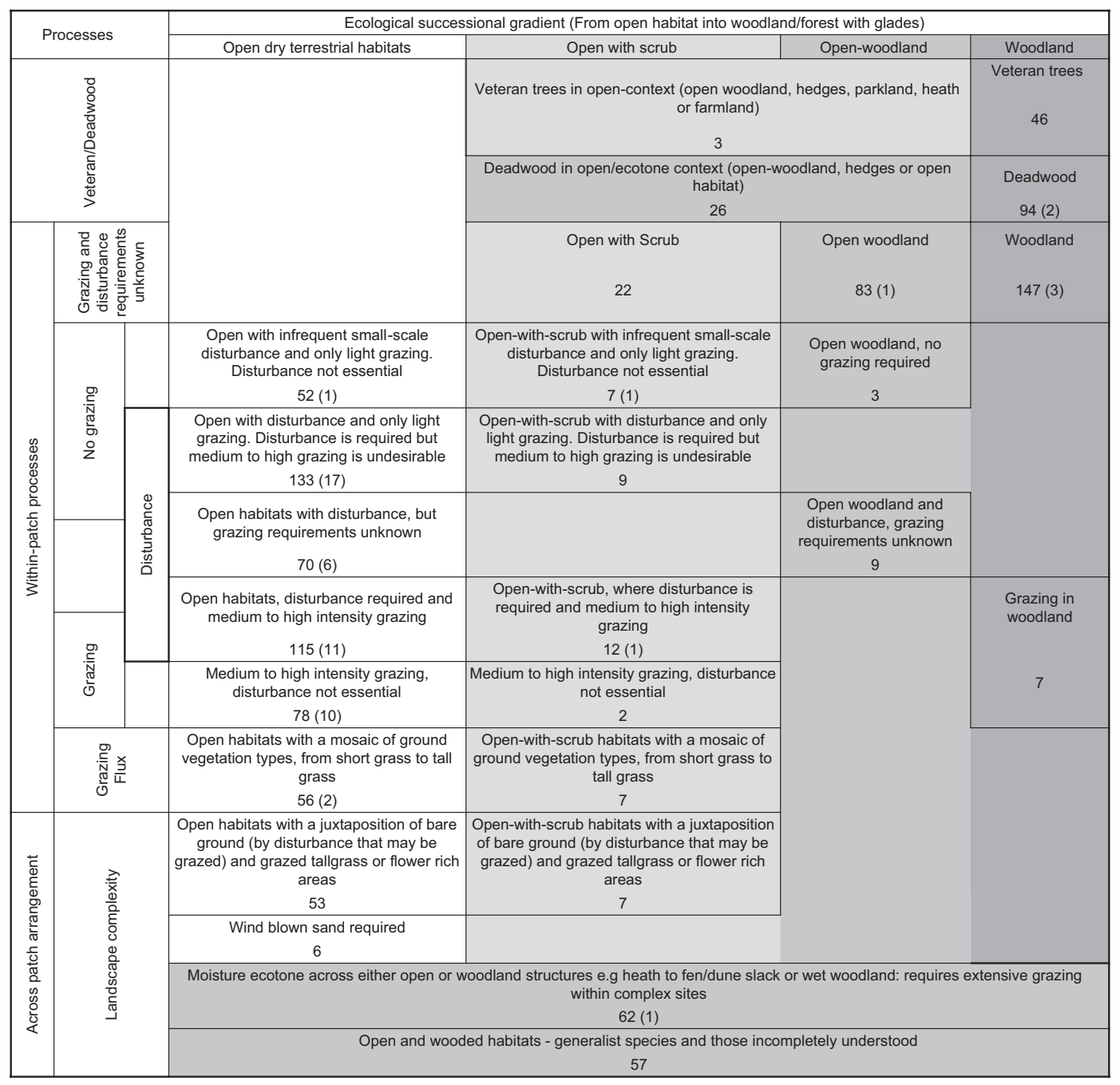

Fig. 5. Allocation to management guilds of terrestrial priority species recorded in Breckland, based on ecological requirements that focus on responses to potential management actions, with the number of Breckland specialists in parentheses.

specialist species that could be delivered by evidencebased management prescriptions applied to the grass heath resource.

\section{Discussion}

To our knowledge, this is the first comprehensive assessment in Europe quantifying the species present in a biogeographical region. We demonstrated that it is possible to collate and analyse autecological understanding of several thousand priority species to define multitaxa management guilds. This important aspect of the biodiversity audit highlighted the poor effectiveness of current conservation investment, and the need for a more systematic approach to regional prioritization and conservation. The local conservation community was involved in all stages of the biodiversity audit process, from inception through to reporting (Fig. 2), thus management recommendations were shared property that immediately influenced conservation practice.
Our findings emphasize the enormous discrepancy between current priorities for conservation and the true volume of underlying biodiversity, much of which was invisible. We found regional species richness was one or two orders of magnitude greater than perceived by conservation practitioners (P.M. Dolman, personal observations) despite being an underestimate with, for example, few soil infauna recorded. Resulting publicity (with national and local media) captured the public's imagination; quantifying true numbers of species astonishes and excites people. By focusing on proxies, we may be missing an opportunity to build a constituency for conservation.

In both regions, previous priority lists were incomplete and idiosyncratic. Here, we considered all designated, rare and regionally restricted species as potential priorities for conservation, wider than the focus on BAP priority species often adopted in the UK. We found that even the numbers of BAP species present in each region had been underestimated two- to seven-fold, and we identified many more regionally restricted species than recognized previ- 


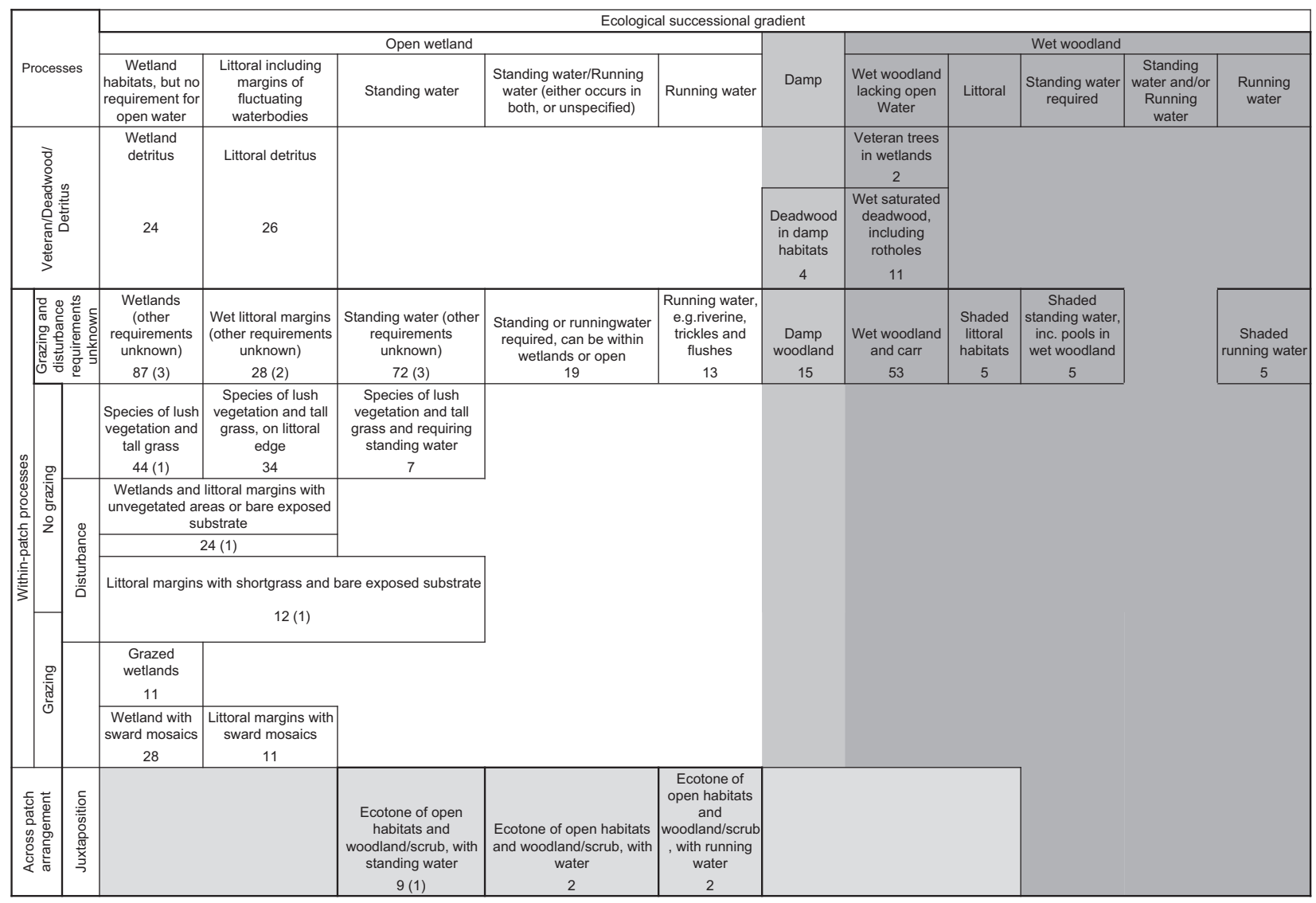

Fig. 6. Allocation to management guilds of priority species recorded in Breckland associated with wet habitats, based on ecological requirements that focus on responses to potential management actions, with the number of Breckland specialists in parentheses.

ously. The persistence of such localized species depends on conservation in the appropriate region. UK conservation implementation prioritizes BAP species (Defra 2011); however, as only $24 \%$ of regionally restricted species were BAP designated, many are under the conservation radar. Such prioritization of widespread, often abundant species, combined with neglect of regional specialists, risks biodiversity homogenization and loss of regional distinctiveness (Gauthier, Debussche \& Thompson 2010). Whichever criteria are chosen for prioritization, these should be systematically applied (Regan et al. 2008); this first requires systematic collation of candidate species and coding of status and relevant criteria, so that appropriate weightings can be applied. Data collation by the biodiversity audit approach lends itself to this.

Semi-natural habitats have been used to select and designate protected sites (Ratcliffe 1977) and underpin EC conservation legislation (EC 1992), but are just accidents of historic land use. Despite their important historic and cultural value, for biodiversity conservation it is not the habitats that matter - but the species they sustain. Habitats should not be viewed as an endpoint for conservation, but a vessel. Our analysis showed few priority species were restricted to individual habitats; rather they occur where particular combinations of ecological structures and processes are found. Conservation of large numbers of priority species cannot be ensured by habitatbased approaches that focus on vegetation composition, but fail to understand and create species requirements (Asher et al. 2001).

We found that the autecological evidence base was available to define integrated, cross-taxa management guilds. The information was scattered and not readily accessible to managers, but could be systematically captured and integrated. Application of a biodiversity audit approach to other regions will expand the numbers of species classified, with potential to build an increasingly comprehensive resource for further stakeholders to apply to their own region. While our classification of management guilds is doubtless imperfect, making such analyses explicit and widely available on web-based media invites responses from the public, taxonomists and natural historians.

It may be necessary to periodically review and update species assignment to management guilds. Many aspects of management requirements will be invariant to climate, for example, regeneration requirements of plants (particularly those with a semelparous or paucennial life history), microhabitat associations of predatory ground-active invertebrates, or requirements of phytophagous invertebrates determined by their host plant ecology. However, microclimatic and microhabitat requirements of inverte- 
brate species may alter with anthropogenic climate change, as already observed for some butterfly species (Thomas et al. 2001; Davies et al. 2006).

This work utilized the considerable body of biological records created by amateur naturalists and members of the public. Previous biodiversity audits have been conducted in the UK (see Table S2, Supporting information), but collated highly incomplete lists, largely comprising BAP priority species. By contrast, our data collation was systematic and comprehensive. These Audits benefitted from strong recording effort in two iconic regions, though the attention these have received is unlikely to be atypical compared with many other regions of Europe also famous among natural historians. Success of data collation depends on the quality of the records centres and recording networks. Where fewer records can be obtained, numbers of species and priorities may be under-estimated. However, although $33 \%$ and $53 \%$ of the total records in the Breckland and The Broads, respectively were obtained since 2000 , only $9 \%$ of the species in each region were first recorded post-2000. We expect characterization of the regional biota in terms of management requirements to be robust, even where recording effort is lower.

Relating biodiversity requirements to current conservation management highlighted important discrepancies between best and widespread practice. There was an indefensible mismatch between the requirements of large numbers of priority species and the conditions created by publicly funded management. This appears to have arisen through a focus on maintaining plant communities, rather than considering the vegetation structures, processes and microhabitats required by priority species. We acknowledge that the broad prescriptions resulting from the management guilds may require refinement to conserve individual species populations, but the discrepancy between evidence-based recommendations and current conservation action is sobering.

Our results demonstrate the considerable benefits of quantifying what species are present in a region, what groups interventions should aim to conserve, and what their needs are. Comparing the ecological requirements of priority species to regional management practice highlighted poor efficiency of conservation. We recommend this systematic approach for other regions, particularly in those European countries where biodiversity is well characterized, autecological understanding is strong and recorder networks are effective.

\section{Acknowledgements}

This work was funded by the Forestry Commission, Natural England, Suffolk County Council, the Norfolk Biodiversity Partnership, Plantlife and The Broads Authority. We are grateful to Neal Armour-Chelu, Gen Broad, Neil Featherstone, Andrea Kelly, Bev Nichols, Tim Pankhurst, Scott Perkin and Jonathan Spencer for advice and valuable suggestions. Martin Horlock of the Norfolk Biodiversity Information Service and Martin Sanford of Suffolk Biological Records Centre assisted in compilation of records. We are indebted to the many recorders and taxonomic experts, without whom this work would not have been possible.

\section{References}

Asher, J., Warren, M., Fox, R., Harding, P., Jeffcoate, G. \& Jeffcoate, S. (2001) The Millennium Atlas of Butterflies in Britain and Ireland. Oxford University Press, Oxford.

BA. (2009) Broads Authority Biodiversity Action Plan: Action Plan 20092014. Broads Authority, Norwich.

Bretagnolle, V., Villers, A., Denonfoux, L., Cornulier, T., Inchausti, P. \& Badenhausser, I. (2011) Rapid recovery of a depleted population of little bustards Tetrax tetrax following provision of alfalfa through an agrienvironment scheme. Ibis, 153, 4-13.

BRIG. (2007) Report on the Species and Habitat Review: Report to the UK Standing Committee June 2007. Biodiversity Reporting and Information Group, Peterborough.

Clark, J.A. \& May, R.M. (2002) Taxonomic bias in conservation research. Science, 297, 191-192.

Davies, Z.G., Wilson, R.J., Coles, S. \& Thomas, C.D. (2006) Changing habitat associations of a thermally constrained species, the silver-spotted skipper butterfly, in response to climate warming. Journal of Animal Ecology, 75, 247-256.

Defra. (2011) Biodiversity 2020: A strategy for England's Wildlife and Ecosystem Services. Department for Environment, Food and Rural Affairs, London.

Dolman, P.M., Panter, C. \& Mossman, H.L. (2010) Securing Biodiversity in Breckland: Guidance for Conservation and Research. First Report of the Breckland Biodiversity Audit. University of East Anglia, Norwich.

Dolman, P.M. \& Sutherland, W.J. (1992) The ecological changes of Breckland grass heaths and the consequences of management. Journal of Applied Ecology, 29, 402-413.

Eaton, M.A., Brown, A.F., Noble, D.G., Musgrove, A.J., Hearn, R.D., Aebischer, N.J., Gibbons, D.W., Evans, A. \& Gregory, R.D. (2009) Birds of Conservation Concern 3: the population status of birds in the United Kingdom, Channel Islands and Isle of Man. British Birds, 102, 296-341.

EC. (1992) Council Directive 92/43/EEC of 21 May 1992 on the Conservation of Natural Habitats and of Wild Fauna and Flora. European Commission, Brussels.

EN. (2001) Breckland Natural Area Biodiversity Action Plans: Targets Action Report. English Nature, Norwich.

Evans, S., Henrici, A. \& Ing, B. (2006) The Red Data List of Threatened British Fungi: Preliminary Assessment. British Mycological Society, Manchester.

Eycott, A.E., Watkinson, A.R. \& Dolman, P.M. (2006) Plant diversity in clearfell forest: ecological patterns and management effects. Journal of Applied Ecology, 43, 1160-1171.

Fuller, R.M., Smith, G.M., Sanderson, J.M., Hill, R.A., Thomson, A.G., Cox, R., Brown, N.J., Clarke, R.T., Rothery, P. \& Gerard, F.F. (2002) Countryside Survey 2000 Module 7: Land Cover Map 2000: Final Report (CEH: Project Report Number C00878). Centre for Ecology and Hydrology (Natural Environment Research Council), Monks Wood.

Gauthier, P., Debussche, M. \& Thompson, J.D. (2010) Regional priority setting for rare species based on a method combining three criteria. Biological Conservation, 143, 1501-1509.

Haes, E.C.M. \& Harding, P.T. (1997) Atlas of Grasshoppers Crickets and Allied Insects in Britain and Ireland. Institute of Terrestrial Ecology, Huntingdon.

Harvey, P.R., Nellist, D.R. \& Telfer, M.G. (2002) Provisional Atlas of British Spiders (Arachnida, Araneae), Volumes 1 \& 2. Biological Records Centre, Centre for Ecology and Hydrology, Monks Wood.

JNCC (2011) Conservation Designations for UK Taxa. Joint Nature Conservation Committee, Peterborough. http://jncc.defra.gov.uk/page-3408.

Lawton, J.H., Brotherton, P.N.M., Brown, V.K., Elphick, C., Fitter, A. H., Forshaw, J., Haddow, R.W., Hilborne, S., Leafe, R.N., Mace, G. M., Southgate, M.P., Sutherland, W.J., Tew, T.E., Varley, J. \& Wynne, G.R. (2010) Making Space for Nature: a Review of England's Wildlife Sites and Ecological Network. Report to Defra.

Lindenmayer, D., Hobbs, R.J., Montague-Drake, R., Alexandra, J., Bennett, A., Burgman, M., Cale, P., Calhoun, A., Cramer, V., Cullen, P., Driscoll, D., Fahrig, L., Fischer, J., Franklin, J., Haila, Y., Hunter, M., Gibbons, P., Lake, S., Luck, G., MacGregor, C., McIntyre, S., MacNally, R., Manning, A., Miller, J., Mooney, H., Noss, R., Possingham, H., Saunders, D., Schmiegelow, F., Scott, M., Simberloff, D., Sisk, T., Tabor, G., Walker, B., Wiens, J., Woinarski, J. \& Zavaleta, E. (2007) A checklist for ecological management of landscapes for conservation. Ecology Letters, 10, 1-14. 
MEA. (2005) Ecosystems and Human Well-being: Biodiversity Synthesis. Millenium Ecosystem Assessment, World Resources Institute, Washington, DC.

NE. (2008) Natural England Framework for Science, Research and Evidence Integrated Science to Support Integrated Solutions: Natural England Research Report NERR011. Natural England, Peterborough.

NEA. (2011) The UK National Ecosystem Assessment: Synthesis of the Key Findings. UNEP-WCMC, Cambridge.

O'Brien, M., Green, R.E. \& Wilson, J. (2006) Partial recovery of the population of corncrakes Crex crex in Britain, 1993-2004. Bird Study, 53, 213-224.

Ratcliffe, D. (1977) A Nature Conservation Review: The Selection of Biological Sites of National Importance to Nature Conservation in Britain. Volume 1. Cambridge University Press, Cambridge.

Regan, H.M., Hierl, L.A., Franklin, J., Deutschman, D.H., Schmalbach, H.L., Winchell, C.S. \& Johnson, B.S. (2008) Species prioritization for monitoring and management in regional multiple species conservation plans. Diversity and Distributions, 14, 462-471.

Rothera, S. (1998) Breckland Natural Area Profile. English Nature, Norfolk Team, Norwich.

Seddon, P.J., Soorae, P.S. \& Launay, F. (2005) Taxonomic bias in reintroduction projects. Animal Conservation, 8, 51-58.

Sutherland, W.J., Pullin, A.S., Dolman, P.M. \& Knight, T.M. (2004) The need for evidence-based conservation. Trends in Ecology and Evolution, 19, 305-308.

Thomas, C.D., Bodsworth, E.J., Wilson, R.J., Simmons, A.D., Davies, Z. G., Musche, M. \& Conradt, L. (2001) Ecological and evolutionary processes at expanding range margins. Nature, 411, 577-581.
Wright, H.L., Lake, I.R. \& Dolman, P.M. (2012) Agriculture-a key element for conservation in the developing world. Conservation Letters, $\mathbf{5}$, $11-19$.

Received 4 January 2012; accepted 15 June 2012

Handling Editor: Des Thompson

\section{Supporting Information}

Additional Supporting Information may be found in the online version of this article.

Table S1. Habitats, microhabitats and ecological structures and processes.

Table S2. Review of previous regional biodiversity audits conducted in the UK.

As a service to our authors and readers, this journal provides supporting information supplied by the authors. Such materials may be re-organized for online delivery, but are not copy-edited or typeset. Technical support issues arising from supporting information (other than missing files) should be addressed to the authors. 